\title{
Motives for Health Plan-Academic Health Center Relationships: Journal Review of the First Quarter Century
}

\author{
Patricia H. Parkerton \\ University of Michigan
}

\begin{abstract}
Motives for health plan (HP)-academic health center (AHC) relationships, including both deterrents and inducements, are explored through a review of 153 articles, published from 1970 through 1997, in academic and health care industry journals about HP-AHC relationships. Every article that met inclusion criteria was coded for year, journal, author, audience, type of article, organization of focus, purposes, priorities, affiliation motives, and issues. Peak years were 1973 (the passage of HMO legislation) and the most recent years from 1994 through 1997. The motives to affiliate were found to be different for AHCs and HPs (e.g., physician attitudes, a deterrent for AHCs and inducement for $H P$; resources, a deterrent for HPs and inducement for AHCs). Increases in size of HPs and decreases in political power of AHCs have resulted in changes to motives to form relationships. Motives must be acknowledged to move from competitive to collaborative relationships.
\end{abstract}

\section{PURPOSE OF STUDY}

It is now commonplace to observe that the past 25 to 30 years have been a period of substantial organizational change in the health care system. There has been an overwhelming amount of commentary and study that has focused on evolution and change in the expanding variety of healthcare organizations including hospitals, physicians' practices, health care insurers,

Jane Banazak-Holl, Ph.D., and Stephen S. Mick, Ph.D., of the Department of Health Management and Policy, School of Public Health, University of Michigan, offered substantive editorial support in the preparation of this article. The full list of 153 references is available on request of the author. This article, submitted to Medical Care Research and Review on July 2, 1998, was revised and accepted for publication on December 9, 1998.

Medical Care Research and Review, Vol. 56 Supplement 2, (1999) 106-137 (C) 1999 Sage Publications, Inc.

106 
and employer groups, as well as academic health centers (AHCs) and health plans (HPs). AHCs educate and train the nation's future physicians and other health care professionals, conduct clinical research, and frequently provide medical services to the sickest and often poorest Americans. HPs combine the attributes of medical delivery systems with health insurance and cover the medical needs of a majority of Americans. Together, these two institutional sectors have had a tremendous impact on the quality and availability of medical services in this country. However, the relationships of AHCs and HPs have not been studied in depth. Two current debates make this review of more than passing interest. First, AHCs are experiencing stress in competing in today's cost-constrained health care markets as their costs for education of health professionals, clinical research, and service to impoverished populations continue to increase (Friedman 1997; Moore and Griner 1997; Pardes 1997). Second, recent legislative debates, such as patient's bill of rights and HMO liability, as well as other consumer concerns, have sparked controversy over the quality of care that patients receive from HPs. These challenges exemplify the importance of examining how AHCs and HPs interact with one another as market and regulatory pressures continue to intensify.

Application of the organizational literature on alliances would suggest that HPs and AHCs might form alliances in response to market, regulatory, or community forces, particularly if they are in the same service area and/or are suppliers and purchasers of each other's products (Oliver 1990). However, this review of trade and academic reporting of HP-AHC relationships shows much, and occasionally conflicting, information on the precise circumstances under which HP-AHC affiliations form. Identification of the motives for affiliation might enhance our ability to understand the past and potential for relationship formation. This review also examines the actions, opinions, and perceptions of industry leaders who do not necessarily have empirical or theoretical support for their arguments, yet they reflect the actions and attitudes prevalent in the industries. In an attempt to understand the relationships between AHCs and HPs, a large number of publications were reviewed with the following questions in mind:

- Is it possible to discern deterrents and inducements to affiliation from these articles?

- How have motives changed over the years?

\section{BACKGROUND}

How AHCs and HPs regard each other is an issue that is described in widely contrasting rhetoric. For example, Friedman (1997) described their relationship as one consisting of near combat and antagonism: 
This Clash of the Titans would be powerful under any circumstances; when opposing sides each represent massive power, money, and intelligence, their battle will be monumental. But in this case, the contest is even more potentially destructive because both the contestants see themselves as being on a mission from God. For each, it is a holy war. (P. 325)

On the other hand, Zablocki (1996) emphasized the cooperative potential of AHCs and HPs: "Numerous challenges face these partnerships, but HPs are using creative strategies to overcome hurdles and build lasting, and in some cases, long-standing, relationships with academic medical centers" (p. 50).

Such contrasting perspectives raise the broader question of what the relationship of these two sectors has been and is becoming, as discerned from a quarter century of writing in academic and health care industry journals. An examination of this literature is important because it can reveal the content or ideology of underlying themes that may shape the future configuration of the health care system.

AHCs are major producers of medical services in the United States. They train doctors, other professionals, and clinical personnel; develop clinical innovations, medical technology, and highly specialized medical services; and provide the full range of medical services delivered in the office, hospital, or home. These organizations join others to sustain the U.S. vision of cures for ever-expanding clinical problems. There are currently 125 AHCs in the United States (Meyer, Potter, and Gary 1997; Pardes 1997), and that number has been relatively stable over the past quarter century. During the period covered by this study, AHCs were evolving from the more traditional institutions of academic medical centers, including medical and other professional schools and university hospitals, to a more integrated spectrum of services, including umbrella organizations with consolidated faculty service plans.

HPs are the intermediaries between the providers of medical services and the patients or their purchasers of services and include health maintenance organizations (HMOs) and preferred provider organizations (PPOs). Managed care includes a broader group of organizations that both insure and exercise control of health services use and can, therefore, include carve-out benefit management, employer-organized systems, administration-only arrangements, and other organizational variants in addition to HPs. HPs procure, package as insurance benefits, coordinate, or directly provide medical services. While HMOs have a legislated definition as prepaid, coordinated delivery systems based on a medical group, medical staff, or individual practice association (IPA), there is no federally legislated definition of PPOs.

HPs encompass an augmented group of organizations that include, in addition to HMOs and PPOs, HMO networks, combination plans, point-of- 
service plans, and other variations. Beginning as small, dependent, borderline organizations, they have grown in number, size, and complexity to be major purchasers of AHCs' products. As of 1996, about 70 million Americans were enrolled in HMOs and another 90 million in PPOs (American Association of Health Plans 1998). Thus, the majority of U.S. citizens are receiving their medical care through HPs. This review addresses those HPs that are both medical delivery systems and provide health insurance.

Both AHCs and HPs are actually complex organizational healthcare systems-a series of interrelating corporations having diverse goals that must interface smoothly with their related corporations and with the community around them. The demands of that internal interface can be daunting to those who wish to redirect energy and resources to external relationships. Despite internal demands, relationships are established, if infrequently. These are formed to meet the often-differing goals of AHCs and HPs and may range from verbal, temporary agreements to one organization acquiring sole control of the other. The motivating goals can involve medical education (undergraduate or graduate), research (clinical or delivery system), provision of medical services (primary or tertiary), and generation of revenue.

\section{METHODOLOGY}

\section{SOURCES: SELECTION OF JOURNALS AND ARTICLES}

This review begins with January 1970, preceding the HMO Act of 1973, which initiated a flow of federal funds to establish HMOs, and concludes more than a quarter century later in December 1997, following the growth of this young industry to cover the majority of Americans. Articles were selected for inclusion if they were published in journals indexed in MEDLINE or HealthSTAR (the National Library of Medicine online bibliographies) during the period 1970 through 1997. If an article had key words relating to AHCs and to HPs as well as text on actual or possible interaction between these organizations, such as joint programs or common organizational sponsorship, then the article was included in this review. Efforts were made to be as inclusive as possible when identifying articles. However, articles in specialty or regional medical or administrative journals were not included. Twenty journals published all articles aimed at audiences in academic medicine, health services research, managed care, medical delivery systems, and the medical profession, as listed in Table 1 . The number of journal articles by audience and time period published are identified in Table 2 . 
TABLE 1 Journals by Type of Audience

\begin{tabular}{|c|c|}
\hline Audience & Journals \\
\hline Academic medicine & Academic Medicine, Journal of Medical Education \\
\hline Physicians & $\begin{array}{l}\text { Journal of the American Medical Association, The New } \\
\text { England Journal of Medicine }\end{array}$ \\
\hline Health services research & $\begin{array}{l}\text { Health Affairs, Health Service Research, Medical Care, } \\
\text { Medical Care Research and Review }\end{array}$ \\
\hline Medical delivery & $\begin{array}{l}\text { Business and Health, Health Care Management Review, } \\
\text { Hospital and Health Networks, Modern Healthcare, } \\
\text { Journal of Health Care Finance, Medical Group } \\
\text { Management Journal }\end{array}$ \\
\hline Managed care & $\begin{array}{l}\text { American Journal of Managed Care, Group Health Journal, } \\
\text { Healthplan, HMO Practice, Managed Care, Managed Care } \\
\text { Quarterly }\end{array}$ \\
\hline
\end{tabular}

TABLE 2 HP-AHC Articles Published from 1970 to 1997 by Journal Audience

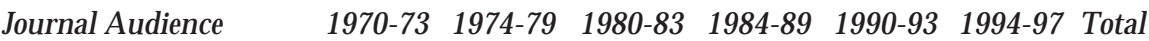

\begin{tabular}{lrrrrrrr}
\hline Academic medicine & 16 & 7 & 3 & 10 & 4 & 30 & 70 \\
$\begin{array}{l}\text { Physicians } \\
\text { Health services }\end{array}$ & 1 & 3 & 4 & 1 & 2 & 19 & 30 \\
$\begin{array}{l}\text { research } \\
\text { Medical delivery }\end{array}$ & 2 & 2 & - & 2 & 4 & 8 & 18 \\
$\begin{array}{l}\text { Managed care } \\
\text { Total }\end{array}$ & - & - & 2 & - & 6 & 21 & 29 \\
\hline
\end{tabular}

\section{CONTENT ANALYSIS}

Content analysis was used to extract consistent information from articles and limit author bias. By coding the mere presence of a topic, the author's subjective bias on the described value of the item was reduced. This made it possible to extract relevant motives and issues without ascribing value. A data set was created by comprehensively coding each article for its content regarding 10 factors: publication year, journal, primary reading audience, author's 
TABLE 3 Article Coding

\begin{tabular}{lc}
\hline Element & \multicolumn{1}{c}{ Distinctive Subdivisions } \\
\hline Publication date & Year article appeared in journal, from 1970 to 1997 \\
Journal & See Table 1 \\
Audience & AHC, medical profession, health services research, \\
& medical delivery system, managed care \\
Author's position & AHC leader, medical school faculty and other physicians, \\
& HP leader, non-AHC health services researcher, hospital \\
Type of article & administrator, editor or reporter \\
& Case (includes some experiments / interviews), review, \\
Organization of focus & editorial, survey (includes some experiments / \\
& interviews) \\
Relationship objective & AHC, physicians, faculty, HMO, managed care, health \\
& Services research, medical school, university hospital \\
& tertiary care, HP development, undergraduate medical \\
Relationship priority & education, graduate medical education \\
Affiliation motive & Education, finance, legitimacy, market, patients, research \\
Issue & Deterrents, inducements, structures, goals \\
& Social (e.g., community, access), ideological (e.g., goals, \\
& priorities), economic (e.g., financial, incentives), political \\
& (e.g., regulation, legislation) \\
\hline
\end{tabular}

Note: $\mathrm{AHC}=$ academic health center; $\mathrm{HP}=$ health plan; $\mathrm{HMO}=$ health maintenance organization .

position, article type, organization of focus, relationship objective, relationship priority, affiliation motive, and issue. These are defined in Table 3. This data set was then available to identify articles from which specific deterrents and affiliations could be gleaned as well as to identify frequency distributions. Deterrents and inducements to affiliate and goals and structures for affiliation were extracted from the text of these articles. A deterrent was expressed as a difficulty, problem, complication, limit, or hazard. An inducement was identified as an advantage, facilitator, reward, or priority. Deterrent and inducement lists were generated by identifying a possible impact once without regard to frequency of reference. Finally, common themes and changes over the past quarter century in these motives contributing to joint activity were identified. 


\section{FINDINGS}

\section{ARTICLE DISTRIBUTION}

Before 1973, there was only one article published on HP-AHC relationships-specifically examining medical education in a prepaid group practice

(Bosch and Banta 1970). The time trend in the number of published articles is bimodal, with the greatest numbers appearing in 1973, 18 (12 percent), and in the years from 1994 through 1997 (54 percent), as the number per year rose from 12 to 27. During the intervening period from 1974 to 1993, an average of 2.5 articles appeared yearly. (While Table 2 summarizes the prevalence by audience and time period, a detailed table by year and journal is available from the author.)

The number of articles written on HP-AHC relationships varies significantly by journal and by readership $(p<0.05)$. Academic medicine published the greatest number of articles: 70 (46 percent) of the articles appeared in the journals of the Association of Academic Medical Centers, which includes Journal of Medical Education and its successor, Academic Medicine. The first article was published in The Journal of the American Medical Association (Bosch and Banta 1970). Before 1976, the only other journal carrying articles on HP-AHC relationships was of health service research, Medical Care (Dorsey 1973; Myers 1973; Perkoff, Kahn, and Mackie 1974). Articles for the medical profession appeared next, in 1976, in The New England Journal of Medicine (Heyssel and Seidel 1976). Not until 1982 did the medical delivery journals publish on this topic in Modern Healthcare and Health Care Management Review (Bendix 1982; Pawlson and Kaufman 1982). Delivery system articles did not begin appearing consistently on this topic until 1991 after a 9-year hiatus. Finally, managed care periodicals came late to this issue. The first article appearing in an HP journal, Group Health Journal, was published in 1983 (Katz and Steinwachs 1983), and there was a 13-year wait until the second article appeared in 1996 (Zablocki 1996). Overall, it took an entire decade before articles on the issue of HP-AHC relationships aimed at all five audiences were published. As a result, a disproportionate share of articles were directed at the medical-profession side of the HP-AHC relationship, including all of those published before the 1980s. The total percentage of articles directed at specific audiences was 46 percent academic medicine, 19 percent medical profession, 19 percent medical delivery system, 12 percent health services research, and only 4 percent managed care. This small percentage of managed care articles reflects the absence of journals. The Group Health Journal existed for a portion of the early years as the only managed care publication. Managed care was a new industry in the 


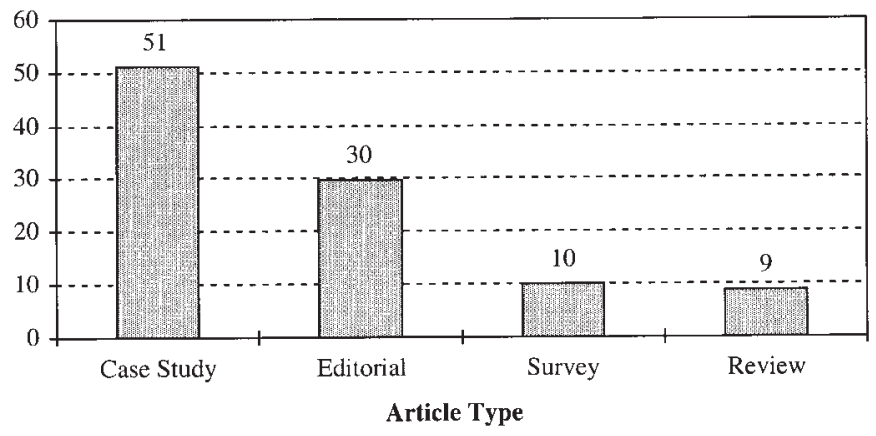

FIGURE 1 Type of Article

1970s, and as such, it was both small and without funding to support or reward industry leaders for publishing.

The distribution of article types is shown in Figure 1. Most frequent were the case studies (51 percent) focusing on one or several actual joint programs; next frequent were the editorials ( 30 percent), including opinions, experience, and interviews. Surveys represented 10 percent of the articles, and reviews of articles or practices accounted for the remaining 9 percent.

The distribution of authors as they described themselves is shown in Figure 2. The author's position did have an impact on the type of article written. Leaders of AHCs and HPs jointly authored the case studies of specific HP-AHC relationships 80 percent of the time. Forty-six percent of the editorials were authored by medical school faculty members. Authors representing managed care and HMOs published no reviews and just one survey. Ten of the articles were jointly written by authors representing both HPs and AHCs: eight of these were case descriptions and two were editorials. However, even health services researchers published only two surveys, which represented just 10 percent of their published articles.

\section{SUBJECT MATTER TRENDS}

Nearly half of the articles present a case study of a particular relationship, while another 25 percent of articles were written primarily to present an 
114 MCRER 56 (Supplement 2: Building Bridges IV, 1999)

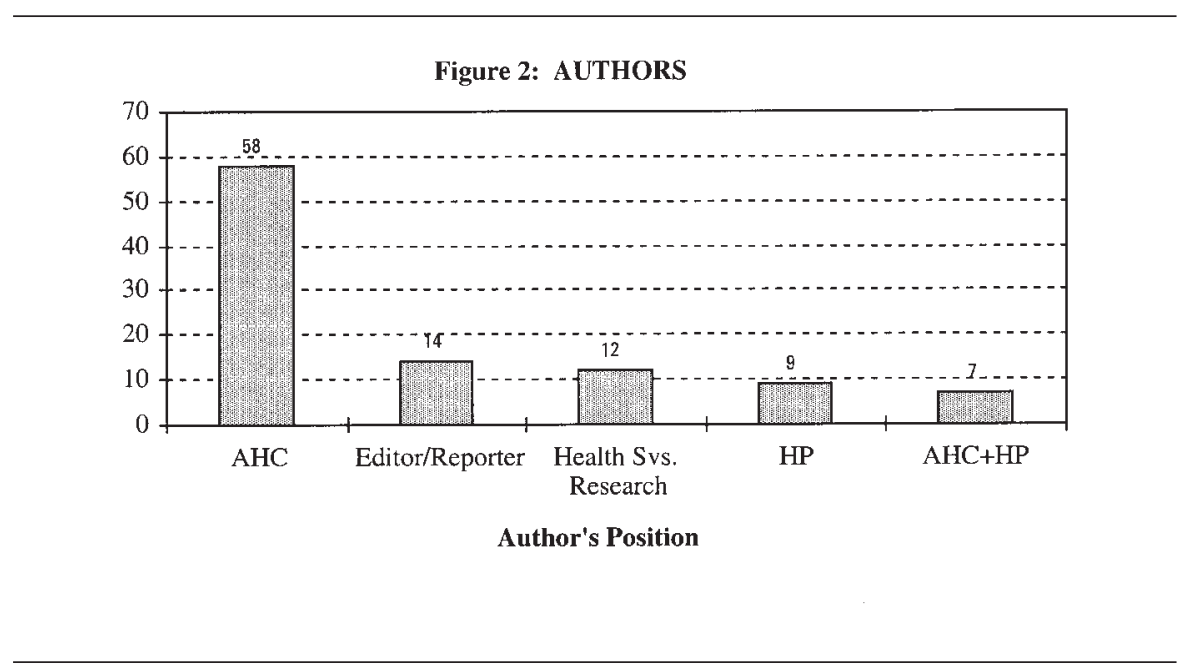

FIGURE 2 Authors

author's particular opinion or point of view on the subject (editorial). About one third of the articles are primarily about AHCs, while nearly half of the articles discuss the relationship between AHCs and HPs. Not surprisingly, the early articles focus much more on the development and growth of managed care, with more than 6 in 10 of the 1970s articles including discussion of this topic. By the mid-1990s, the growth of HPs eliminated this as a reason for affiliation. Many articles highlighted factors and motives that serve to bring AHCs and HPs together, including delivery of services, medical education, research, the community, and political pressures. Issues of survival and financial security were often expressed as secondary to these primary (or public) missions.

Delivery-of-service articles, which were rare in the 1970s, began to increase in the 1980s but then experienced a lull in the early 1990s before rebounding recently. In the early years, these articles focused on primary care (Falk 1973; Pawlson and Kaufman 1982; Friedman 1984) rather than tertiary care and specialty services (Sheps 1973; Willard 1973; Heyssel and Seidel 1976; Pawlson and Kaufman 1982); over the past 8 years, the attention has been much more even. Articles referencing medical education have also grown in number, with the split between medical school and residency programs remaining fairly even throughout the years. ${ }^{1}$ Research-focused articles relative to affiliation were generally much rarer than those written about education. The topic of clinical research made a brief appearance in the 1970s, disappeared until 


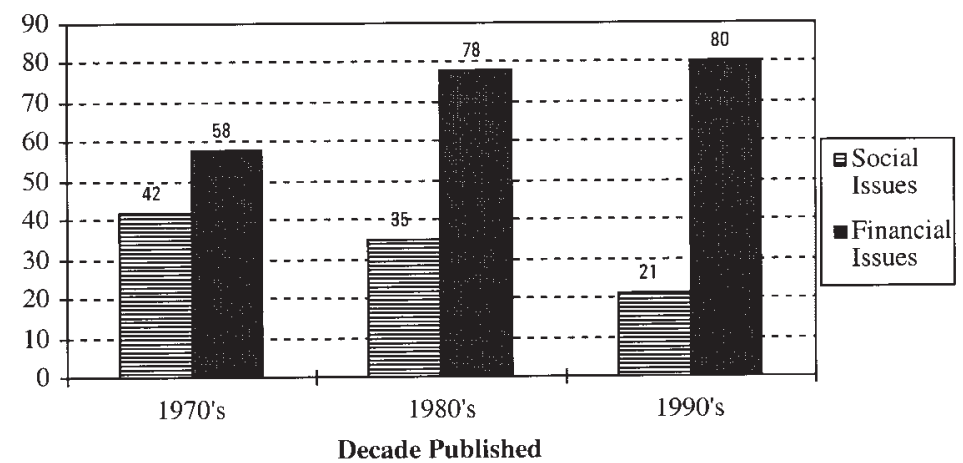

FIGURE 3 Social and Financial Issues

very recently, but accounts for more than 20 percent of articles published in the 1994-97 time period. ${ }^{2}$ Delivery system research has displayed a more steady pattern, consistently accounting for 10 percent to 15 percent of the total. $^{3}$

References to issues-social, political, financial, and ideological-have varied independently over the decades. These motives may present as either deterrents or inducements to affiliation as priorities and rhetoric change. Social issues, such as inner-city problems, Medicaid programs, and special population needs, have been referenced less often over the past two decades, declining from 40 percent to 20 percent of the articles. ${ }^{4}$ Political references to federal, state, and/or local issues have risen steadily. ${ }^{5}$ Financial issues were discussed in the 1980s and 1990s in about 80 percent of the articles, rising from 58 percent in the 1970s. ${ }^{6}$ Ideology, or internal mission and objectives, has been referenced fairly steadily if on different issues. Figure 3 shows the change in discussion of social issues relative to financial issues.

\section{RELATIONSHIP OBJECTIVES}

The authors focused somewhat more frequently, 55 percent, on organizations that were either AHC (e.g., Hoft and Glaser 1982; Heyssel 1989; Hillman 


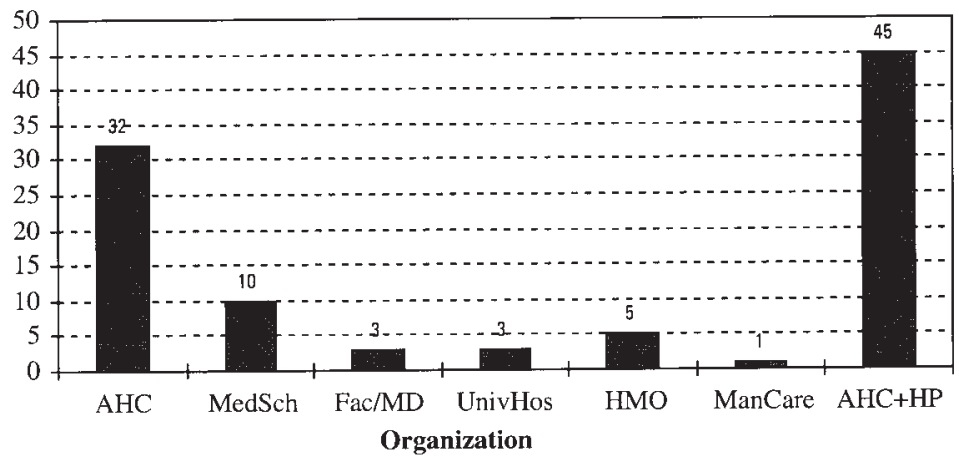

FIGURE 4 Organizational Focus of Articles

et al. 1991; Fox and Wasserman 1993; Meyer and Blumenthal 1996) or HP (e.g., Dorsey 1973; Wolfe and Jones 1982; Kirz and Larsen 1986; Corrigan and Thompson 1991) rather than on both HP and AHC organizations.

Forty-eight percent of the articles focused on AHC or component organizations such as medical schools. While the objectives for forming these relationships varied by HP or AHC, only 6 percent of the articles focused on the perspective of the HP alone. Figure 4 displays the distribution of articles by organization of focus.

Seven possible objectives for HP-AHC relationships were coded and displayed in Figure 5. Most frequently cited was medical education: graduate training, 39 percent, and undergraduate education, 38 percent. Provision of clinical services by AHCs to HPs was the next most frequent, with primary care services cited in 29 percent of the articles and tertiary care services in 24 percent of the articles. Fifteen percent of the articles focused on clinical research and another 13 percent on delivery system (including insurance benefits) research. Although HP development was referenced just 22 percent of the time overall, that reflected a drop from 68 percent in the 1970s to 17 percent in the 1990s. 


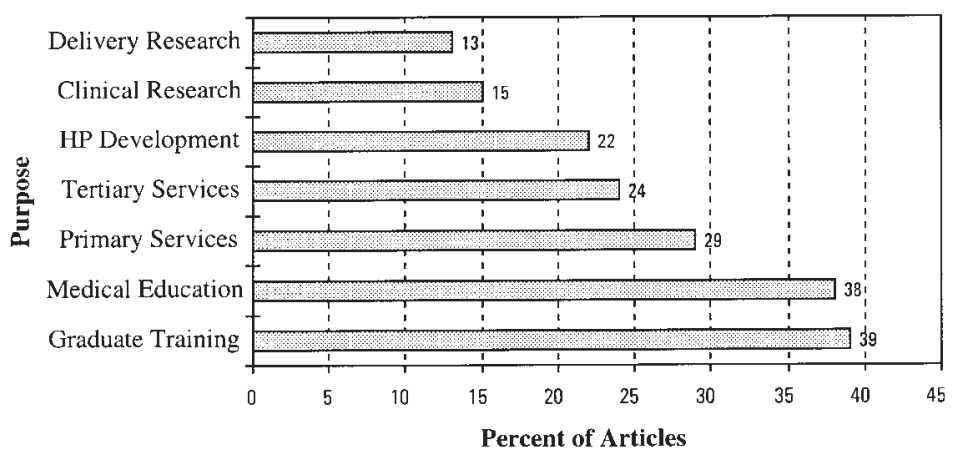

FIGURE 5 Purpose of HP-AHC Relationship

The percentage of articles focusing on medical education dropped during the 1990s. Specifically, the objectives of AHCs that are most often sought through HP-AHC links include (1) sites for medical teaching, (2) sites for clinical research, (3) patients for tertiary care medical services, and (4) patients for inpatient care. As AHCs have diversified and provided a broader range of medical services, relationships to HPs have also been formed to acquire primary care services. From the perspective of the HP, relationships to AHCs are most commonly sought to (1) provide covered primary care, (2) provide tertiary care medical services, (3) develop and expand HPs, and (4) gain legitimacy to improve marketability.

\section{AHC MOTIVES}

Many deterrents were identified in these articles, which were referenced relatively consistently over the time period of this review. ${ }^{7}$ Four types of deterrents emerged: (1) resource demand resulting from additional expense, administrative conflicts, capital investment, risk of failure, or internal distribution conflicts; (2) physician resistance stemming from faculty attitudes, 
concern about HP quality, required practice changes, consideration of ambulatory and primary care as inferior, threatened community physicians, or resistance to medical oversight; (3) structural complexity, including legal concerns, community involvement, consumer interference, lack of a smooth inpatient-outpatient interface, required reorganization, or departmental fiefdoms; and (4) goal conflict focused around medical education, research, tertiary services, or requirements for new management expertise.

The inducements identified, often in the same articles, were placed in counterbalancing categories including the following: (1) physician recruitment or retention from access to patients or research data; (2) resource advantage resulting from inexpensive community involvement, increased referrals and revenue, more effective dealing with competition, increased cost awareness, or acquired insurance payments; (3) structural support from eluding regulation; and (4) goal enhancement as a consequence of producing primary care physicians, obtaining cross-sectional patient population for tertiary care services, improving primary care, teaching preventive services, improving continuity of care, raising community health level, accessing teaching sites relevant for primary/ambulatory care, or teaching students to be generalists working within time constraints. No inducements beyond those from goal enhancement were actually identified for AHC physicians.

\section{HP MOTIVES}

Although many of the motives are common to both HPs and AHCs, the literature mentions fewer deterrents or inducements for HPs to participate in an HP-AHC relationship. ${ }^{8}$ This may simply reflect the paucity of publications aimed at the HP audience. Concerns are vague but consistent, with a new and developing industry focused on survival and growth during the 1970s. In the 1980s, the concerns focused on the lack of HP control within the teaching hospital, including high hospitalization rates, loss of patient control by HP physicians, excessive laboratory tests, and high costs. Involvement in medical education was perceived to limit membership growth — a survival issue in earlier days. In the 1990s, the deterrents focused on loss of control, structural incompatibilities, loss of productivity due to teaching, and costs that included those resulting from AHCs' treatment of sicker patients, expense, inefficiency, and propensity for the use of new technology. While AHCs offered HPs a marketing advantage with their image of high-quality and clinical innovation, most HPs feared this would attract sicker enrollees, an expensive competitive disadvantage (Fox and Wasserman 1993). Of note, no HP benefits were enumerated in articles written in the 1970s (Thompson 1973; Willard 1973). 


\section{CHANGES IN MOTIVES}

Comparing the reported deterrents to reported inducements for AHCs and for HPs by decade gives a glimpse into the limited likelihood of affiliation. Table 4 counts each deterrent or inducement just once regardless of the number of references. The 1970s articles identified more deterrents than inducements for each type of motive. Although the 1970s included references to concerns about community involvement (arising in all four categories), community issues are not mentioned thereafter. This may have been partially because the consumer movement as political action in health care became quiescent with the end of the federal health planning acts in the late 1980s. By the 1980s, one type of motive had more inducements than deterrents for both organizations. For AHCs, that motive was resource advantage, and for HPs, it was physician attitude. All three articles written for a HP audience that commented on physician attitudes discussed strategies for creating inducements for physicians to collaborate (rather than deterrents to physicians' supporting partnerships). Furthermore, in the 1980s, seven out of the eight articles that discussed financial issues and were written for an AHC audience discussed inducements rather than deterrents to affiliation.

In the 1990s, the primary motive for HPs continued to be growth, which increased the inducement value of resource advantages and deterrence of structural complexity. However, the AHCs became more focused on goal enhancement as the pressures to train more primary care physicians and to be more competitive in research funding increased. Also in the 1990s, 7 of 10 articles written for an AHC audience that discussed organizational priorities emphasized the inducements for collaboration. A new deterrent affecting AHC physician attitudes first appeared in the 1990s and concerned medical oversight from without-including preauthorization, procedure review, and coverage challenge.

\section{DISCUSSION}

\section{REVIEW OF AFFILIATION ARTICLES OVER DECADES}

Relationships between complex organizations are difficult to create and to sustain. Assessing them at a single point in time might reveal the current style of management or publishing, but scanning the publications over a period of, in this case, the life of one of the industries tells a much clearer story. Journal articles reveal there have been affiliations, their type, their prevalence, and who is writing about them. Just as important, the motives for the formation of these relationships, including both deterrents and inducements, have been 
TABLE 4 HP-AHC Motives over Three Decades

\begin{tabular}{|c|c|c|c|c|}
\hline \multirow[b]{2}{*}{ Issues } & \multicolumn{2}{|c|}{$A H C s$} & \multicolumn{2}{|c|}{$H P s$} \\
\hline & Deterrents & Inducements & Deterrents & Inducements \\
\hline \multicolumn{5}{|l|}{ 1970s } \\
\hline Physician attitude & 5 & 1 & 1 & 0 \\
\hline Resource demand/advantage & 1 & 0 & 1 & 0 \\
\hline Structural complexity/support & 3 & 1 & 1 & 0 \\
\hline Goal conflict/enhancement & 3 & 1 & 0 & 0 \\
\hline Total & 12 & 3 & 3 & 0 \\
\hline \multicolumn{5}{|l|}{ 1980s } \\
\hline Physician attitude & 8 & 3 & 0 & $3^{\mathrm{a}}$ \\
\hline Resource demand/advantage & 1 & $7^{\mathrm{a}}$ & 4 & 0 \\
\hline Structural complexity/support & 3 & 3 & 1 & 1 \\
\hline Goal conflict/enhancement & 2 & 4 & 2 & 0 \\
\hline Total & 14 & $17^{\mathrm{a}}$ & 7 & 4 \\
\hline \multicolumn{5}{|l|}{ 1990s } \\
\hline Physician attitude & 11 & 0 & 3 & $4^{\mathrm{a}}$ \\
\hline Resource demand/advantage & 3 & 2 & 4 & 2 \\
\hline Structural complexity/support & 2 & 0 & 3 & 1 \\
\hline Goal conflict/enhancement & 3 & $7^{\mathrm{a}}$ & 2 & 0 \\
\hline Total & 19 & 9 & 12 & 7 \\
\hline
\end{tabular}

Note: $\mathrm{AHC}=$ academic health center; $\mathrm{HP}=$ health plan.

a. Inducements exceed deterrents.

identified. As inducements increase and deterrents decrease, the likelihood of AHC-HP affiliation increases.

Deterrents are likely to limit any type of relationship formation. For example, without financial stability, an HP might lose the independence to successfully negotiate any agreement with an AHC. Furthermore, in the 1970s, inducements were not sufficient to make a case for the establishment of a single AHC-HMO relationship because the three identified AHC inducements were not considered to be essential: inexpensive means to link with the community, primary care training sites, and a cross-sectional patient population-all during a period of AHC strength. Furthermore, there were no inducements identified for HMOs.

\section{RELATIONSHIP OBJECTIVES}

The most obvious mutual need for HP-AHC relationships is the receipt/provision of specialty or tertiary care services, yet this objective was 
cited in only 3 percent of the articles from the 1970s and increased to just 33 percent of the 1990 articles. In contrast, 100 percent of the HP authors referred to tertiary care services in the 1990s. Income production would have been a powerful inducement for most organizations, but it was not often mentioned.

HPs need the results of AHC teaching and research, but they have not traditionally considered it part of their responsibility to educate physicians or conduct research. Therefore, HP-AHC contracts often develop around the HP's need to guarantee that an AHC will provide tertiary care services to HP members. Subsequently, AHCs' increasing needs to generate income through other services played an important role in redefining these contracts. AHCs compete to attract patients for services that are also provided at other community facilities. Despite HPs' requirements for the sophisticated tertiary care services provided at the AHC for their members, the higher costs of care at university hospitals deter HPs from sending patients there for services available elsewhere. In fact, Gold (1996) found AHCs to be the sole providers for only a few tertiary services in the markets studied, and, therefore, managed care plans usually had choices regarding with whom they contracted. There will continue to be conflicts between AHCs and HPs over situations in which clinical evaluation has not determined that AHC services are necessary but the HP member believes them to be necessary. These patient demands compel HPs and AHCs to work together, at least occasionally. Finally, contractual arrangements have been established for the use of services, primarily of the AHC for the HP member, but increasingly, HPs are providing their expertise to AHCs in joint ventures and as part of AHC primary care outreach. Despite the many ways in which AHCs and HPs might collaborate, however, very little movement toward collaboration has actually occurred (Graves 1993).

The goal of meeting educational needs has motivated AHCs and deterred HPs from affiliating with one another. On one hand, AHCs offer continuing education and training programs for practicing physicians and other health professionals that benefit HPs by contributing to a well-trained staff. However, HPs often do not want to incur the added expense of educating staff, which may increase marketing deterrents and dissuade individuals from joining plans (Moore 1990). A substantive issue has been the lack of implementation of past recommendations for changes in medical education emphasizing breadth of knowledge, skills, and attitudes particularly related to social medicine and preventive health (Bosch and Banta 1970). Medical schools' unwillingness to change curriculum has discouraged HPs from making connections to AHCs. Moore et al. (1994), however, raise the question of whether academic medicine might be transformed in the 21st century by the HMO as it was by the teaching hospital in the past century. 
Part of the problem in understanding how much HPs and AHCs focus on education in their relationships to one another is an absence of available data on training opportunities in HPs. As of 1997 (Karp et al. 1997), the Bureau of Health Professions reported that it had been unable to find any central database on training opportunities in managed care settings or on managed care partnerships with AHCs. This study also reported finding anecdotal evidence for only eight such partnerships. A study coordinated by Group Health Association of America (Corrigan and Thompson 1991) on HP involvement in graduate medical education found that 15 percent of HMOs trained residents, often as part of an AHC affiliation. Several studies argue that HP participation in graduate medical education may be less expensive and intrusive than HP participation in undergraduate medical education (Hoft and Glaser 1982; Isaacs and Madoff 1984; Buchanan 1987) and that HP members are satisfied with training arrangements (Wolfe and Jones 1982; Kirz and Larsen 1986; Sheets, Caruthers, and Schwenk 1990). Currently, HPs play a meager role in education.

Another motivation behind HP-AHC relationships is the opportunity for collaboration on research on clinical practice, delivery system change, financing, the organization of services, and health professions. Collaborative research takes advantage of defined populations and readily available data sources within HPs. Falk (1973) discussed one of the first collaborations of this sort between Yale and a local HMO. Overall, many believe the reality has fallen short of the potential for joint research between HPs and AHCs. Mechanic and Dobson (1996) have identified the potential for research collaboration, focusing on HPs' patient information systems and AHCs' research infrastructures.

In 1973, Thompson identified the options for organizational relationships between academic medical centers and HMOs as sponsorship or affiliation. Since that time, varieties of contracts have been designed for more limited relationships. Certainly, HPs act as rotation sites for medical students and residents as well as full-time clinical sites for residents. ${ }^{9}$ In addition, joint research projects have been undertaken and reported in literature not reviewed here (Gold 1996; Mechanic and Dobson 1996).

The opportunity to improve community relations is also an objective for a relationship. The AHCs and the HPs must constantly reinforce their value to those in their service areas. To the extent that medical care is a local commodity, national reputations of HPs will be of negligible value relative to the strength of local image. Therefore, the HP needs to enlist community support to entice members. The AHC needs to attract patients for teaching, research, and clinical revenue as well as to bridge the social distance between "town 
and gown." The HP is in a position to guarantee patients to the AHC; concomitantly, the AHC can offer the legitimacy associated with quality and stability to the HP. When HMOs were first created through federal legislation, a local community board was a requirement for federal qualification. This requirement made close association with an HMO threatening to AHCs, which feared community control of their actions (Willard 1973). Over the years, qualification has become less essential for the formation and survival of HPs; consequently, HPs have evolved ways to separate the community role from actual organization control and the delivery of medical care. Despite this reduction of community threat to AHC autonomy, its replacement with HP control is equally threatening, particularly with large, distant, national HPs. However, increasing HP market penetration makes it necessary for AHCs to deal with HPs to maintain their clinical revenue from patient care.

\section{AHC MOTIVES}

The first research question was, "Is it possible to discern deterrents and inducements to affiliation from these articles?" Although those motives identified in this review may not be exhaustive, they certainly represent a wide spectrum of possible deterrents and inducements. Elements of both an organization's internal and external environments can facilitate or become barriers to affiliation. Internal elements include both structure and strategy and involve such motives as financial status, management approach, values, and board relationships. External motives may include marketplace competition, staff recruitment, and new technology. Furthermore, affiliation always introduces an element of change, a natural deterrent-particularly to a large, established organization. For a relationship to be formed, then, organizations must embrace some degree of change to address counterproductive attitudes and patterned behavior (Weitekamp and Ziegenfuss 1995). Furthermore, the greatest deterrents arise from those institutional characteristics that have supported organizational achievement in the past (Moore 1990).

This review has addressed those motives identified for AHCs. In 1973, concern was expressed that unless HMOs became a setting for teaching and research, they would compromise the unique role of medical schools (Willard 1973) by competing for patients and funding. Carey and Engelhard (1996) confirmed 23 years later that, indeed, medical schools were under such stress. To support the teaching and research goals, AHCs need to undergo major, difficult reorganization and changes in allocation of resources. The territorialism and professional autonomy of both physicians and specialty departments make this very challenging. AHC faculty members are resistant to even 
internal oversight, yet as managed care has grown, so have external, managed care interventions. Because the promise of many inducements has not been achieved, the deterrents become more formidable.

The inducements most frequently mentioned for the 1970s were not compelling; affiliation in the community and help with training primary care physicians were not fundamental goals for the AHCs during this period. Between 1982 and 1986, however, the list of inducements grew as it became likely that HMOs were here to stay. Many of these rich articles about the motives for AHCs were published not in Academic Medicine but in journals directed at other audiences (Hoft and Glaser 1982; Pawlson and Kaufman 1982; Moore 1986; Karp et al. 1997). With many deterrents identified in journals, it is remarkable that even pacesetter AHCs managed to establish any affiliations. It is not, however, surprising that these affiliations were principally (six out of eight) with HMOs that AHCs had sponsored (Karp et al. 1997).

Over this quarter century, AHCs have been described as well established, complex, and resistant to change. Medical schools within AHCs are planning curricular changes to increase the material taught on population-based care, preventive interventions, team delivery, and social needs. Yet, it has been necessary to restate these needs for change over the decades. Medical education is threatened as governmental and payer concern increases about the number and type of physicians being trained. This concern is leading to an actual loss of federal funding threatening some medical schools with closure or merger. University hospitals are also threatened by loss of revenue from shorter hospital stays and competition from other hospitals fueled by HP demands. Additionally, although research is considered essential and focused on clinical innovations, funding is felt to be inadequate. Despite this litany of pressures, medical school faculty continue to be strong, specialty oriented, not inclined to change, and resistant to HP relationships.

\section{HP MOTIVES}

No HP benefits were enumerated in articles written in the 1970s (Thompson 1973; Willard 1973). It is not surprising, therefore, that only AHCsponsored HPs established relationships with AHCs, with the exception of two long-established group/staff model HMOs on the West Coast-KaiserPermanente of Northern California and Group Health Cooperative of Puget Sound. In the 1980s, it was recognized that an AHC alliance might be useful in recruiting and retaining physicians as well as establishing a quality image in the community (Hoft and Glaser 1982; Pawlson and Kaufman 1982; Heyssel 1989). By the 1990s, these inducements had been expanded to include 
payment, academic privileges for teaching, or reduced tertiary care expenses (Moore 1990; Hillman et al. 1991).

Over this past quarter century of growth, HPs became more diverse in their structures and objectives, but they were always differentiated by size, locus of control (local vs. national), and organizational structure (staff, group, and IPA model HMOs, networks, PPOs). They have continued to grow, to change, and to become increasingly national in scope. The competitive pressures on HPs have not diminished but have escalated and have become principally cost based rather than benefit focused, reducing the need or desire for affiliation with AHCs.

\section{MOTIVES OVER TIME}

The articles have been revealing on the second research question, "How have motives been presented by decade?" The common inducements to affiliate across the decades have included pressures to broaden medical school curriculum, expectations for research to be done on the delivery of medical care, and the growth of HPs. While these motives have been inducements for both AHCs and HPs, they have also served as deterrents to HPs that feared negative market impact. Additionally, as HPs grew, their size made them less needy of AHC relationships.

Deterrents that have appeared throughout this quarter century include characteristics of AHCs (strong faculty and large established organizations both resistant to change) as well as HP characteristics (principally diversity). The structural diversity originally encoded in the HMO legislation has only increased over the years, making it difficult to comprehend HPs and confusing to negotiate with them. Furthermore, HP differences have meant a wide variation in organizational objectives, making it difficult to attach common motivations to them. The one clear commonality between AHCs and HPs over the decades has been a consistent level of mistrust.

Changing themes are also evident over this time period. Financially and politically strong AHCs, such as those in the 1970s, found it easier and less threatening to establish an HMO that they could control than to work with an $\mathrm{HMO}$ that they did not control. By developing a new HMO, the AHC controlled its structure, financial incentives, and leadership. Because AHCs have decades of complexity and internal political strife with which to deal, their needs for autonomy from external forces are very high. Changes in HP structures-including more structural diversity, HP mergers, for-profit status, and national scope-have all been deterrents to AHCs. This has been coupled with reduced inducement for HPs to affiliate. However, in the 1990s, AHC 
inducements markedly increased as university hospitals became financially threatened, medical schools became concerned about closing or merging, educational and research funds became both scarcer and tied to national expectations, and competition increased.

\section{CONCLUSIONS}

Determining the predictive value of both journal articles and past HP-AHC relationships is highly subjective. Published motives of the past may be quite biased relative to insider reality. For example, authors are more likely to write of hopes rather than fears or of accomplishments rather than failures. Consequently, the articles reviewed might lead to a biased interpretation of HP-AHC relationships. Furthermore, given the changes displayed over the years within these articles, future conjecture is likely to be flawed.

In the 1970s, HPs were dependent and vulnerable, while the AHCs were dominant and stable. In the 1990s, this relationship is nearing reversal in some locations, a dynamic that certainly influences affiliation potential. Two major themes have emerged for AHCs: increasing pressure to reduce and document their costs to provide care and to educate physicians, and a loss of public and political support to maintain their status quo. Increasingly, federal regulation is reducing the support for both education and research within AHCs. The need to find other financial resources and to prove AHCs' importance to the public good, along with the increasing control of HPs over clinical dollars, has shifted the asymmetry of the relationship between AHCs and HPs. As the abundance of physicians increases, HPs are less dependent on AHCs to recruit and retain their medical staff. Whether AHCs can accept this changed power balance and whether HPs will use it in the public interest remains to be seen. However, AHCs are more likely to be aware of areas of mutual benefit with HPs and potential for increased efficiency or stabilizing influences and, therefore, more likely to pursue possible HP alliances as their underlying needs increase. Most organizations will respond to environmental demands that threaten their survival. AHCs that perceive a future loss of financial and

political clout if they remain unchanged are likely to search out new strategies to survive and strengthen their organizations. Despite these pressures, AHC-HP negotiations may be limited to financial agreements for clinical services unless regulatory pressures induce them to expand their relationships for education and research.

Altering the current environment to favor affiliations without causing new problems will be difficult. Where once the major inducements to an AHC relationship for a HP was the recruitment and retention of physicians, this is no 
longer meaningful. As AHCs continue to train large numbers of physicians, they have also reduced their negotiating power with HPs. Therefore, to ask HPs to act as education sites or share their research databases, some other inducement must be offered. Spokespersons from both industries have suggested that a facilitator may be necessary if an agenda is to be developed to move forward and improve understanding of each organization's operational goals and priorities (Mechanic and Dobson 1996). D'A Reinhard (1997) has proposed that facilitation needs to involve the leadership of government. Both the Academic Health Center/Managed Care Organization Partnership Initiative funded by The Pew Charitable Trusts (Cohen 1997) and the National Institutes of Health have sponsored efforts to foster collaboration between managed care and the research community (Moy et al. 1997; Skirboll 1997).

Although, ideally, delivery systems should be invested in sharing current practices with other providers, HP-AHC relationships have been few. AHCs have had more stable funding, rewards for publishing, and little competition between themselves as the number of AHCs has remained consistent. In addition, their service areas do not often overlap. However, that same stability has created less inducement for AHCs to change or form new relationships. Even though information about models of HP affiliation might have been more easily shared between AHCs than within the managed care industry with its rapid growth, reorganizations, and within-industry competition, there is little evidence of increased AHC-HP relationships forming as a result of this AHC communication.

Relationships may form with different structures and strengths and with more competition, conflict, or collaboration. Those relationships in which the partners are competitive are hard to form and difficult to sustain. Partners need to have complementary but not necessarily identical goals. Although AHCs still hope for mastery over the encroachment of managed care, concern and even desperation are expressed in some articles. Defensive actions reign among AHCs as they gird themselves to protect their positions. ${ }^{10}$ The mistrust between AHCs and HPs may even be appropriate in the current era of mergers and acquisitions in which one cannot assume the organization with which an alliance is developing will exist in that form next year. With the average medical school dean staying in a position for 3 years and managed care administrators moving about the country with, perhaps, greater frequency, is it possible to establish shared goals and symbiotic objectives? AHCs and HPs can compete unproductively, draining each other's economic resources and public confidence. Our health care system has been called feudal in its competitive excesses (D'A Reinhard 1997), and there is fear that the value of this cutback style of competition is limited. The days of peaceful accord between 
AHCs and HPs may be past without skillfully negotiated settlements. The danger is not only to AHCs and HPs but also to the nation's health care system, if such misplaced energies are not curtailed.

Conflictual relationships in which motives clash are unfortunately the most common. If, despite conflict, the relationship continues, it may flourish for having dealt with the troublesome issues. However, in the case of AHCs and HPs, inherent tension between the HPs' need to control costs and the AHCs' desire to provide the most technologically sophisticated patient care often sustains conflict (Pawlson and Kaufman 1982). Resolving these conflicts is crucial to the continuation of a useful relationship and requires strong leadership, open communication, and realistic desire to overcome obstacles.

For strong relationships to occur, deterrents must be minimized and inducements maximized. Therefore, the AHC must respect the HP's need to provide high-quality services at competitive prices, and the HP must contribute to the teaching and research programs of the AHC. If AHCs assure the training of the next generation of physicians and continuing education of present physicians as well as inspire clinical research and the most sophisticated treatments for the critically ill, they will secure this nation's place as the world leader in medical care. If HPs coordinate services, maximize use of resources, constrain costs, improve access to care, and decrease variability of care, they will make it possible for the U.S. health care system to continue to offer high-quality care to even more people. While it will not be easy to sustain both organizational autonomy and national system advantage, it is necessary to do so to move toward a collaborative health delivery environment.

\section{NOTES}

1. Osterweis et al. 1980; Corrigan and Thompson 1991; Greenlick 1992; Cohen 1995; Reid et al. 1995; Barzansky, Jonas, and Etzel 1996; Fogelman et al. 1996; Stevens et al. 1996; Veloski et al. 1996; Karp et al. 1997; Phillips et al. 1997.

2. Willard 1973; Weitekamp and Ziegenfuss 1995; Cutler 1996; Donahue et al. 1996; Mechanic and Dobson 1996; D'A Reinhard 1997; Moy et al. 1997; Skirboll 1997.

3. Sheps 1973; Willard 1973; Heyssel and Seidel 1976; Pawlson and Kaufman 1982; Hillman et al. 1991; Weitekamp and Ziegenfuss 1995; Donahue et al. 1996; Skirboll 1997.

4. Falk 1973; Lyon, Scullion, and Weston 1973; Perkoff 1973; Piemme and Schroeder 1973; Sheps 1973; Wolfe and Zubkoff 1973; Evans 1975; Heyssel and Seidel 1976; Osterweis et al. 1980; Pawlson and Kaufman 1982; Heyssel 1989; Hillman et al. 1991; Greenlick 1992; Fox and Wasserman 1993; Japsen 1994; Moore et al. 1994; Iglehart 1995a; Weitekamp and Ziegenfuss 1995; Gold 1996; Meyer and Blumenthal 1996; D'A Reinhard 1997; Friedman 1997; Iglehart 1997; Karp et al. 1997. 
5. Bosch and Banta 1970; Falk 1973; Piemme and Schroeder 1973; Sheps 1973; Wilson 1973; Wolfe and Zubkoff 1973; Yedidia 1973; Heyssel and Seidel 1976; Corrigan and Thompson 1991; Hillman et al. 1991; Fox and Wasserman 1993; Japsen 1994; Iglehart 1995a; Weitekamp and Ziegenfuss 1995; Donahue et al. 1996; Fogelman et al. 1996; Fried and Besdine 1996; Gold 1996; Meyer and Blumenthal 1996; Veloski et al. 1996; D’A Reinhard 1997; Friedman 1997; Iglehart 1997; Karp et al. 1997; Skirboll 1997.

6. Hoft and Glaser 1982; Pawlson and Kaufman 1982; Herrmann, Matthews, and Segadelli 1983; Isaacs and Madoff 1984; Moore 1986; Heyssel 1989; Moore 1990; Hillman et al. 1991; Widra and Fottler 1992; Fox and Wasserman 1993; Iglehart 1994; Japsen 1994; Rogers, Snyderman, and Rogers 1994; Barzansky, Jonas, and Etzel 1995; Billi et al. 1995; Iglehart 1995a, 1995b; Weitekamp and Ziegenfuss 1995; Barzansky, Jonas, and Etzel 1996; Blumenthal and Thier 1996; Carey and Engelhard 1996; Chessare and Herrick 1996; Cutler 1996; Donahue et al. 1996; Fogelman et al. 1996; Gold 1996; Mechanic and Dobson 1996; Meyer and Blumenthal 1996; Thomas, McGuire, and Hellmann 1996; Veloski et al. 1996; Zablocki 1996; D'A Reinhard 1997; Friedman 1997; Iglehart 1997a, 1997b; Karp et al. 1997; Phillips et al. 1997; Skirboll 1997.

7. Falk 1973; Lyon, Scullion, and Weston 1973; Thompson 1973; Willard 1973; Heyssel and Seidel 1976; Hoft and Glaser 1982; Pawlson and Kaufman 1982; Moore 1986, 1990; Hillman et al. 1991; Fox and Wasserman 1993; Moore et al. 1994; Carey and Engelhard 1996; Rowe 1973.

8. Thompson 1973; Willard 1973; Hoft and Glaser 1982; Pawlson and Kaufman 1982; Heyssel 1989; Moore 1990; Hillman et al. 1991; Rowe 1973.

9. Thompson 1973; Moore 1986, 1990; Corrigan and Thompson 1991; Moore et al. 1994; Karp et al. 1997; Meyer, Potter, and Gary 1997.

10. Iglehart 1995a; Bauer and Debas 1996; Carey and Engelhard 1996; Chessare and Herrick 1996; Culbertson 1996; Gold 1996; Hagland 1996; Kertesz 1996; Pardes and Nathan 1996; Farrell 1997.

\section{REFERENCES}

American Association of Health Plans. 1998. Health Plan Statistics [online]. Available: www.aahp.org

Barzansky, B., H. S. Jonas, and S. I. Etzel. 1995. Educational Programs in U.S. Medical Schools, 1994-1995. Journal of the American Medical Association 274 (9): 716-22.

- 1996. Educational Programs in U.S. Medical Schools, 1995-1996. Journal of the American Medical Association 276 (9): 714-19.

Bauer, E. A., and H. T. Debas. 1996. The Merger of Stanford's and UCSF's Clinical Enterprises: Impact on Education. Journal of the American Medical Association 276 (21): 1770-71.

Bendix, J. 1982. Medical School and HMO Affiliate: 200 Students to Enroll in Program [news]. Modern Healthcare 12 (2): 38. 
Billi, J. E., C. G. Wise, E. A. Bills, and R. L. Mitchell. 1995. Potential Effects of Managed Care on Specialty Practice at a University Medical Center. The New England Journal of Medicine 333 (15): 979-83.

Blumenthal, D., and S. O. Thier. 1996. Managed Care and Medical Education: The New Fundamentals. Journal of the American Medical Association 276 (9): 725-27.

Bosch, S. J., and H. D. Banta. 1970. Medical Education in Prepaid Group Practice. Journal of the American Medical Association 212 (12): 2101-04.

Buchanan, J. R. 1987. Educational Impacts of New Care Systems. Journal of Medical Education 62 (2): 100-08.

Carey, R. M., and C. L. Engelhard. 1996. Academic Medicine Meets Managed Care: A High-impact Collision. Academic Medicine 71 (8): 839-45.

Chessare, J. B., and R. R. Herrick. 1996. Business Strategies for the Survival of the Academic Medical Center. Academic Medicine 71 (3): 215-17.

Cohen, J. J. 1995. Educational Mandates from Managed Care. Academic Medicine 70 (5): 381. . 1997. Pew Catalyzes Education Partnerships with Managed Care Organizations. Academic Medicine 72 (5): 372.

Corrigan, J. M., and L. M. Thompson. 1991. Involvement of Health Maintenance Organizations in Graduate Medical Education. Academic Medicine 66 (11): 656-61.

Culbertson, R. A. 1996. How Successfully Can Academic Faculty Practices Compete in Developing Managed Care Markets? Academic Medicine 71 (8): 858-70.

Cutler, C. M. 1996. Research Needs for Managed Care. Health Affairs 15 (1): 93-94.

D'A Reinhard, J. 1997. Academic Medical Centers and HMOs: Our Shared Future [editorial]. HMO Practice 11 (2): 52-54.

Donahue, D. C., B. E. Lewis, I. S. Ockene, and G. Saperia. 1996. Research Collaboration between an HMO and an Academic Medical Center: Lessons Learned. Academic Medicine 71 (2): 126-32.

Dorsey, J. L. 1973. The Prepaid Group Practice Plan in the Education of Future Physicians: Initial Efforts at the Harvard Community Health Plan. Medical Care 11 (1): 12-20.

Evans, R. L. 1975. Use of Community/Private Sector Resources. Journal of Medical Education 50 (12 pt. 2): 49-56.

Falk, I. S. 1973. Academic Medical Center-HMO Relationship: Sponsorship or Affiliation? Journal of Medical Education 48 (4, Supp.): 53-59.

Farrell, N. L. 1997. University MSO: An Academic Medical Center's Managed Care Strategy. Managed Care Quarterly 5 (2): 25-33.

Fogelman, A. M., L. D. Goode, B. L. Behrens, C. D. DeAngelis, J. D. Forsyth, B. L. Gewertz, J. L. Houpt, J. J. Hutton, W. N. Kelley, D. Korn, L. J. Marton, A. P. Tartaglia, A. G. Wallace, W. R. Wallin, and F. M. Walters. 1996. Preserving Medical Schools' Academic Mission in a Competitive Marketplace. Academic Medicine 71 (11): 1168-99.

Fox, P. D., and J. Wasserman. 1993. Academic Medical Centers and Managed Care: Uneasy Partners. Health Affairs 12 (1): 85-93.

Fried, B. M., and R. W. Besdine. 1996. A Perspective on Academic Medicine from the Nation's Largest Managed Care Purchaser. Academic Medicine 71 (3): 260-61.

Friedman, E. 1997. Managed Care and Medical Education: Hard Cases and Hard Choices. Academic Medicine 72 (5): 325-31. 
Friedman, R. B. 1984. Impact of the Evolution in Health Care Delivery on the Academic Medical Center. Journal of Medical Education 59 (7): 539-46.

Gold, M. R. 1996. Effects of the Growth of Managed Care on Academic Medical Centers and Graduate Medical Education. Academic Medicine 71 (8): 828-38.

Graves, H. W. 1993. Academic Medical Centers and Managed Care Plans: Can an Association Be Mutually Beneficial? Medical Group Management Journal 40 (4): 26-28, 3032,34 .

Greenlick, M. R. 1992. Educating Physicians for Population-Based Clinical Practice. Journal of the American Medical Association 267 (12): 1645-48.

Hagland, M. 1996. Partnerships: Synergy in Seattle. Hospitals and Health Networks 70 (12): 55-56.

Herrmann, T. J., C. W. Matthews, and L. J. Segadelli. 1983. Weighing the Views of a University Hospital and Medical School Regarding an HMO. Journal of Medical Education 58 (9): 686-94.

Heyssel, R. M. 1989. Changing Environment and the Academic Medical Center: the Johns Hopkins Hospital. Academic Medicine 64 (1): 7-11.

Heyssel, R. M., and H. M. Seidel. 1976. The Johns Hopkins Experience in Columbia, Maryland. The New England Journal of Medicine 295 (22): 1225-31.

Hillman, A. L., N. Goldfarb, J. M. Eisenberg, and M. A. Kelley. 1991. An Academic Medical Center's Experience with Mandatory Managed Care for Medicaid Recipients. Academic Medicine 66 (3): 134-38.

Hoft, R. H., and R. J. Glaser. 1982. The Problems and Benefits of Associating Academic Medical Centers with Health-Maintenance Organizations. The New England Journal of Medicine 307 (27): 1681-89.

Iglehart, J. K. 1994. Rapid Changes for Academic Medical Centers. The New England Journal of Medicine 331 (20): 1391-95.

. 1995a. Academic Medical Centers Enter the Market: The Case of Philadelphia. The New England Journal of Medicine 333 (15): 1019-23.

—.1995b. Duke University Conference on the Private Sector. Health Affairs 14 (1): 304-11.

- 1997a. Forum on the Future of Academic Medicine: Session I-Setting the Stage. Academic Medicine 72 (7): 595-99.

- 1997b. Listening in on the Duke University Private Sector Conference. The New England Journal of Medicine 336 (25): 1827-31.

Isaacs, J. C., and M. A. Madoff. 1984. Undergraduate Medical Education in Prepaid Health Care Plan Settings. Journal of Medical Education 59 (8): 615-24.

Japsen, B. 1994. Teaching Hospitals Face Hard Lessons. Modern Healthcare 24 (6):36-38, 40.

Karp, S., L. Langschwager, S. Gamliel, and E. S. Fernandez. 1997. The Need for Comprehensive Data on Educational Affiliations between Academic Health Centers and Managed Care Organizations. Academic Medicine 72 (5): 341-46.

Katz, H., and D. Steinwachs. 1983. Health Services Research at the Columbia Medical Plan: A Decade of Experience. The Group Health Journal 4 (1): 29-35.

Kertesz, L. 1996. UCLA Merger Begins Paying Dividends. Modern Healthcare 26 (11): 58, 60. 
Kirz, H. L., and C. Larsen. 1986. Costs and Benefits of Medical Student Training to a Health Maintenance Organization. Journal of the American Medical Association 256 (6): 734-39.

Lyon, J. G., T. B. Scullion, and W. D. Weston. 1973. Problems and Issues in the Academic Medical Center's Relationship to HMO Projects. Journal of Medical Education 48 (4, Supp.): 21-27.

Mechanic, R. E., and A. Dobson. 1996. The Impact of Managed Care on Clinical Research: A Preliminary Investigation. Health Affairs 15 (3): 72-89.

Meyer, G. S., and D. Blumenthal. 1996. TennCare and Academic Medical Centers: The Lessons from Tennessee. Journal of the American Medical Association 276 (9): 672-76.

Meyer, G. S., A. Potter, and N. Gary. 1997. A National Survey to Define a New Core Curriculum to Prepare Physicians for Managed Care Practice. Academic Medicine 72 (8): 669-76.

Moore, G. T. 1986. HMOs and Medical Education: Fashioning a Marriage. Health Affairs 5 (1): $147-53$.

-1990. Health Maintenance Organizations and Medical Education: Breaking the Barriers. Academic Medicine 65 (7): 427-32.

Moore, G. T., and P. Griner. 1997. Medical Education and Managed Care: Can Sour Turn Sweet? Academic Medicine 72 (7): 568-69.

Moore, G. T., T. S. Inui, J. M. Ludden, and S. C. Schoenbaum. 1994. The "Teaching HMO": A New Academic Partner. Academic Medicine 69 (8): 595-600.

Moy, E., A. J. Mazzaschi, R. J. Levin, D. A. Blake, and P. F. Griner. 1997. Relationship between National Institutes of Health Research Awards to U.S. Medical Schools and Managed Care Market Penetration. Journal of the American Medical Association 278 (3): 217-21.

Myers, B. A. 1973. Health Services Research and Health Policy Interactions. Medical Care 11 (4): 352-58.

Oliver, C. 1990. Determinants of Interorganiational Relationships: Integration and Future Directions. Academy of Management Review 15 (2): 241-65.

Osterweis, M., G. Chickadonz, R. R. Huntley, and C. D. Spencer. 1980. HMO Development for Primary Care Team Teaching of Medical and Nursing Students. Journal of Medical Education 55 (9): 743-50.

Pardes, H. 1997. The Future of Medical Schools and Teaching Hospitals in the Era of Managed Care. Academic Medicine 72 (2): 97-102.

Pardes, H., and C. Nathan. 1996. The Columbia-Cornell Alliance: A Strategic Response to a Changing Health Care Environment. Journal of the American Medical Association 276 (21): 1769, 1771.

Pawlson, L. G., and R. P. Kaufman. 1982. HMOs and the Academic Medical Center: A Reassessment. Health Care Management Review 7 (2): 77-80.

Perkoff, G. T. 1973. Should an HMO Be an Integral Part of the University Medical Center? Journal of Medical Education 48 (4, Supp.): 67-72.

Perkoff, G. T., L. Kahn, and A. Mackie. 1974. Medical Care Utilization in an Experimental Prepaid Group Practice Model in a University Medical Center. Medical Care 12 (6): 471-85. 
Phillips, R. R., M. Y. Lee, H. A. Berman, and M. A. Madoff. 1997. The Tufts Partnership for Managed Care Education. Academic Medicine 72 (5): 347-56.

Piemme, T. E., and S. A. Schroeder. 1973. Issues of Governance of UniversitySponsored HMOs. Journal of Medical Education 48 (4, Supp.): 43-52.

Reid, W. M., R. M. Hostetler, S. C. Webb, and P. C. Cimino. 1995. Time to Put Managed Care into Medical and Public Health Education. Academic Medicine 70 (8): 662-64.

Rogers, M. C., R. Snyderman, and E. L. Rogers. 1994. Cultural and Organizational Implications of Academic Managed-Care Networks. The New England Journal of Medicine 331 (20): 1374-77.

Rowe, D. S. 1973. The Yale Health Plan: A “University Family” HMO. Journal of Medical Education 48 (4): 73-80.

Sheets, K. J., B. S. Caruthers, and T. L. Schwenk. 1990. Assessing Patients' Satisfaction with Care Provided by Residents in an Academic HMO Setting. Academic Medicine 65 (7): 482-83.

Sheps, C. G. 1973. Faculty Tradition and the HMO. Journal of Medical Education 48 (4, Supp.): 34-40.

Skirboll, L. R. 1997. The Impact of Managed Care on Research: The Changing Face of Medicine. Academic Medicine 72:778-79.

Stevens, D. P., D. C. Leach, G. L. Warden, and N. S. Cherniack. 1996. A Strategy for Coping with Change: An Affiliation between a Medical School and a Managed Care Health System. Academic Medicine 71 (2): 133-37.

Thomas, P. A., M. McGuire, and D. B. Hellmann. 1996. A Blueprint for Building an AMC-HMO Teaching Affiliation. Academic Medicine 71 (6): 577-79.

Thompson, J. D. 1973. Alternative Patterns in Relationships between an Academic Medical Center and an HMO. Journal of Medical Education 48 (4, Supp.): 60-66.

Veloski, J., B. Barzansky, D. B. Nash, S. Bastacky, and D. P. Stevens. 1996. Medical Student Education in Managed Care Settings: Beyond HMOs. Journal of the American Medical Association 276 (9): 667-71.

Weitekamp, M. R., and J. T. Ziegenfuss. 1995. Academic Health Centers and HMOs: A Systems Perspective on Collaboration in Training Generalist Physicians and Advancing Mutual Interests. Academic Medicine 70 (1, Supp.): S47-53.

Widra, L. S., and M. D. Fottler. 1992. Determinants of HMO Success: The Case of Complete Health. Health Care Management Review 17 (2): 33-44.

Willard, W. R. 1973. Ideals and Realities of Academic Medical Center Involvement with HMOs. Journal of Medical Education 48 (4, Supp.): 13-20.

Wilson, V. E. 1973. HMOs: Hopes and Aspirations. Journal of Medical Education 48 (4, Supp.): $7-10$.

Wolfe, E. S., and H.W.D. Jones. 1982. Graduate Medical Education in an HMO: An Internal Medicine Residency Program. Journal of Medical Education 57 (6): 468-71.

Wolfe, S., and M. Zubkoff. 1973. Problems of Financing Prepaid Group Practice in the University. Journal of Medical Education 48 (4, Supp.): 93-99.

Yedidia, A. 1973. Federal Support for HMOs. Journal of Medical Education 48 (4, Supp.): 83-92.

Zablocki, E. 1996. Sharing Expertise. Healthplan 37 (5): 48-55. 